October- 2008

\title{
Editorial - Standing by Ponds
}

\author{
Jon Baggaley \\ Professor of Educational Technology \\ Athabasca University \\ (Guest Editor).
}

You can't step in the same water twice, said Heraclitus. He may have been correct in the literal sense, but even Heraclitus must have had those déjà vu moments when his life seemed to be repeating itself. Standing by a pond while making a video download for this IRRODL editorial recalled identical experiences filming by ponds in 1975 and 1996, and prompted some thoughts on how little institutional policy ever really changes in the world of media-based education.

In the mid-90s, television was on its way out as a medium of choice in North American and European education. It had been struggling for credibility for almost as long as it had been in use. The Open University in the UK, for example, started broadcasting course materials on TV in the early '70s, in the middle of the night and often for surprisingly small student enrolments of a few dozen. In 1978 the cost-effectiveness of this effort was questioned at a London University conference with the provocative title "Is anybody there?" It turned out they weren't, at least not in justifiable numbers, and that many courses could have been delivered to the students more efficiently in the mail on audio-tapes.

Since the late '90s, the same question has been asked about the World-Wide Web, at least in regions where only tiny proportions of the population have Internet access. Turning a blind eye to the inaccessibility hurdle, developing-world institutions have pressed on developing web-based ODL materials anyway, with an eager "If we build it, they will come" attitude. They appear motivated to adopt the most modern techniques available, regardless, and are encouraged in this by western distance educators who apparently regard media older than the web as strange and obsolete. But "Is anyone there, or likely to be so?" Actually not for the foreseeable future.

Web-based education has polarised world society into elite and have-not groups far more than TV and radio ever did; and its adoption in the developing world appears oblivious to the fact that today's students would derive greater benefit from media that are actually available to them. Are the hundreds of millions of would-be students who cannot access the Internet a kind of 'untouchable' class, whose problems and needs have become invisible?

Fortunately, in India and other developing countries, the needs of disadvantaged students remain very much in focus, and offer inspiration for all educators. For example, the University estimated by that bastion of source credibility, Wikipedia ('mega-universities' entry), as having the 7th largest student enrolment in the world, is named after Dr. B.R. Ambedkar, who devoted his life to erasing untouchability from Indian society and to implementing open learning methods for the benefit of all. Today Dr. B.R. Ambedkar Open University maintains its commitment to these 
Baggaley

ideals by preserving far-reaching uses of radio, TV, and audio/ videotape, while other Asian universities struggle and fail to harness more elitist forms of Internet-based education.

\section{The Current Edition}

The power of traditional approaches at universities such as BRAOU does not go unrecognised. As the current edition of IRRODL indicates, a major change is taking place internationally in the selection of DE technologies, including non-Internet-based audio and video. The first of the edition's eight Main Section papers, a valuable contribution by Stephen Asunka, indicates the vital need for DE delivery systems to be continually and critically assessed. Asunka's article indicates the pressure felt by Sub-Saharan institutions to implement Internet-based delivery methods, in response to encouragement during the past decade by organisations including UNESCO and the World Bank. The paper points out that pilot-tests of Web-based learning in Ghana are meeting with negative student response, and that Sub-Saharan institutions need help in order to deal with the contextual and motivational questions responsible. The answer to these questions is partly evident in the simple fact that, as Asunka points out, Internet access in SubSaharan Africa, ten years on, is still limited to 3\% of the population - as clear an explanation as one might ever need regarding the practical and motivational obstacles to online learning in the region.

Negative student experiences with online learning are commonplace not only in Africa but throughout Asia, if not uniformly so. In Japan, for example, Internet access is far less of a problem than in other Asian nations, and student responses to e-learning attempts are more positive. Many Japanese educators remain reluctant to adopt online methods, however, as indicated in the article by Bray, Aoki and Dlugosh. The relatively slow adoption rate of Internetbased education in Japan may change with the current emphasis on Internet-based methods in the development of the nation's new Open University.

Having recently returned to Canada from a four-year tour of DE initiatives in 21 Asia-Pacific countries, I deeply sympathise with these institutions in their attempts to harness e-learning - but I especially sympathise with their students. Back in the world where the Internet is actually accessible to most students, one can applaud the advances, both technological and theoretical, being made in the attempt to improve ODL methods. These are seen in the current edition's theoretical critiques by Sushita Gookol Ramdoo (Beyond the Theoretical Impasse: Extending the applications of Transactional Distance Theory), and by Rita Kop and Adrian Hill (Connectivism: Learning theory of the future or vestige of the past?).

Three papers in the Journal's current edition provide practical and applied perspectives. These include an analysis from Canada by Leslie and Murphy (Post-secondary Students' Purposes for Blogging); an article from Iceland by Edvardsson and Oskarsson (Distance Education and Academic Achievement in Business Administration); and a case study of distance examination scheduling and redistribution from Virginia in the US, by Abdous and Wu He. A second US paper follows, by Shachar, discussing the need for ODL knowledge-sharing based on meta-analytic approaches. The issue also reviews two recent books: Expectations and Demands in Online Teaching by Gudea and Ryan; Video in Research in the Learning Sciences by Goldman, Pea, Barron and Derry.

Finally, returning to the main theme of this editorial, the edition features two Technical Reports. In the Journal's previous edition, reports by Sally Berman and Scott Motlik examined the development of DE technologies in Asia. Both authors extend their reviews in the current edition, 
Baggaley

Motlik with an update on the evolution of Internet-based methods in China and South Korea, and Berman with an update on innovative DE technologies in Bhutan, India, and Sri Lanka. These authors are critical of current Internet-based approaches in these countries, and they encourage a simple and constructive alternative: i.e. continuing to use the highly accessible traditional educational media. As Motlik bluntly asks, if China and South Korea, "two of the most developed nations in Asia cannot efficiently implement online learning in more than a decade, what hope do less developed nations have of doing so?”

\section{Conclusions}

Standing by the pond at Athabasca University in Alberta, home of this Journal, one can be grateful that times don't really change that much at all, and that there are still world-class educators who use media which really do reach the student population. Via imaginative fusions of radio, TV, and the web, we can learn from them how ODL delivery practices must be driven by accessibility rather than novelty.

I cannot end this Editorial, however, without returning to the opening paper by Asunka. It quotes a cri de coeur from a student, pleading with the instructor for an extension to an online project deadline. "This is because my project has been affected very much by the power fluctuation we are experiencing in both on campus and at home...This has not only caused low performance (but) I am facing some sort of a psychological battle at the moment, because I really did take the paper." As Asunka stresses, many students are loath to make such pleas, and only do so "in their moments of desperation"

How long will we continue to ignore such bewilderment and frustration on the part of our students, while seeking to implement novel but patently inappropriate technologies purely for the sake of it? And how long will we ignore the obvious fact that it is the blind eye being turned to Internet inaccessibility by institutions and funding agencies that is failing the students, rather than an intrinsic lack of motivation and application on the students' part? Institutional and agency support for Internet-based methods is not just a matter of attempting to think ahead to a day when the new technologies will have become appropriate for all, but a culpable and dishonest disregard for the present, and for the students needs within it. 